\title{
No Association of Positive Superficial and/or Deep Margins with Local Recurrence in Invasive Breast Cancer Treated with Breast-Conserving Surgery
}

\section{Tae In Yoon, $\mathrm{MD}^{1}$ \\ Jong Won Lee, MD, PhD² \\ Sae Byul Lee, MD, PhD² \\ Guiyun Sohn, MD, PhD² \\ Jisun Kim, MD, PhD² \\ II Young Chung, MD2 \\ Hee Jeong Kim, MD, PhD² \\ Beom Seok Ko, MD, PhD² \\ Byung Ho Son, MD, PhD² \\ Gyungyub Gong, $\mathrm{MD}, \mathrm{PhD}^{3}$ \\ Sung-Bae Kim, MD, PhD ${ }^{4}$ \\ Su Ssan Kim, MD, PhD ${ }^{5}$ \\ Seung Do Ahn, MD, PhD \\ Minsung Chung, $\mathrm{MD}, \mathrm{PhD}^{1}$ \\ Sei Hyun Ahn, MD, PhD²}

\author{
${ }^{1}$ Department of Surgery, Hanyang University \\ College of Medicine, Seoul, ${ }^{2}$ Division of \\ Breast and Endocrine Surgery, Department of \\ Surgery, Departments of ${ }^{3}$ Pathology, \\ ${ }^{4}$ Oncology, and ${ }^{5}$ Radiation Oncology, \\ Asan Medical Center, University of \\ Ulsan College of Medicine, Seoul, Korea
}

\begin{abstract}
Purpose
We evaluated the effect of positive superficial and/or deep margin status on local recurrence (LR) in invasive breast cancer treated with breast-conserving surgery (BCS) followed by radiotherapy.
\end{abstract}

\section{Materials and Methods}

In total, 3,403 stage 1 and 2 invasive breast cancer patients treated with BCS followed by radiotherapy from January 2000 to December 2008 were included in this study. These patients were divided into three groups according to margin status: clear resection margin status for all sections (group 1, $n=3,195$ ); positive margin status in superficial and/or deep sections (group 2, n=121); and positive peripheral parenchymal margin regardless of superficial and/or deep margin involvement (group 3, n=87). The LR-free survival between these three groups was compared and the prognostic role of margin status was analyzed.

\section{Results}

Across all groups, age, tumor size, nodal status, and human epidermal growth factor receptor 2 status did not significantly differ. High grade, positive extensive intraductal component, hormone receptor positivity, hormone therapy received, and chemotherapy not received were more prevalent in groups 2 and 3 than in group 1. Five-year LR rates in groups 1, 2, and 3 were $1.9 \%, 1.7 \%$, and $7.7 \%$, respectively. Multivariate analysis revealed that group 3 was a significant predictor for LR (hazard ratio [HR], 4.78; $p<0.001$ ), but that positive superficial and/or deep margin was not (HR, 0.66; $p=0.57)$.

\section{Conclusion}

Superficial and/or deep margin involvement following BCS is not an important predictor for LR.
Correspondence: Jong Won Lee, MD, PhD Division of Breast and Endocrine Surgery, Department of Surgery, Asan Medical Center, University of Ulsan College of Medicine, 88 Olympic-ro 43-gil, Songpa-gu,

Seoul 05505, Korea

Tel: 82-2-3010-5603

Fax: 82-2-474-9027

E-mail: jjjongwr@hanmail.net

Received January 23, 2017

Accepted April 11, 2017

Published Online April 14, 2017

*Presented in part at the Global Breast Cancer Conference, Jeju, Korea, April 28-30, 2016.

\section{Key words}

Local neoplasm recurrence, Margins of excision, Segmental mastectomy 


\section{Introduction}

Breast conserving surgery (BCS) followed by whole breast radiotherapy (RT) is a well-established local treatment option for early-stage breast cancer [1-3]. Of the many factors associated with a high risk of local recurrence (LR) after BCS, involved margin is the most important [4-6]. Most surgical oncologists agree that there is no further benefit from margins beyond "no ink on invasive tumor or ductal carcinoma in situ," which was supported by the 2015 St. Gallen International Expert Consensus on the primary therapy of early breast cancer [7].

From the perspective of surgical oncologists, BCS should aim not only to resect enough normal surrounding structures along with the tumor to secure oncological safety, but also to minimize unnecessary excessive resection in order to attain good cosmetic results. As the unnecessary excision of a skin segment can alter the position of the nipple or the inframammary crease, appropriate skin incisions rather than excisions are the currently suggested routine procedures of BCS $[8,9]$. In addition, more remaining post-BCS retromammary fat tissue on the pectoral fascia enable better cosmetic outcomes. However, due to concerns regarding the possible unfavorable prognostic effects of superficial and/or deep margin involvement, some surgeons still attempt to remove the skin, subcutaneous fat, retromammary fat, and even the pectoral fascia for clear margin status. If proven oncologically safe, making appropriate skin incisions as opposed to excision and leaving as much subcutaneous or retromammary fat as possible could be crucial for satisfactory cosmesis. McIntosh et al. [9] suggested that the involvement of anatomically non-breast parenchymal margins, i.e., superficial and deep margins, may have a smaller effect on LR than breast peripheral parenchymal margins. However, it is not possible to address this issue using a randomized study design; thus, a lack of evidence and conflicting personal opinions have confused surgeons about the effect of positive superficial and/or deep margins on LR.

In this large cohort study, we aimed to evaluate the effect of positive superficial and / or deep margins on local failure in breast cancer patients treated with BCS followed by RT.

\section{Materials and Methods}

Our study protocol was approved by the Institutional Review Board of Asan Medical Center, Seoul, Korea (IRB No. 2016-0229). The clinicopathological and survival data were obtained from the Asan Medical Center-Breast Cancer Cen- ter (AMC-BCC) database. The AMC-BCC is a web-based database system that is prospectively maintained by surgical oncologists and includes information on all consecutive patients who have undergone breast cancer surgeries at Asan Medical Center since 1989 and now contains more than 25,000 entries. The following patient and tumor characteristics were available: age at diagnosis, tumor size, lymph node status, histologic grade, presence of extensive intraductal component (EIC), hormone receptor status, human epidermal growth factor receptor 2 (HER2) status, and presence of hormone therapy or chemotherapy. The inclusion criteria for this study were as follows: (1) BCS for stage 1 or 2 invasive breast cancer from January 2000 to December 2008 and (2) subsequent planned adjuvant radiotherapy. Patients who received neoadjuvant chemotherapy were excluded.

At the time of BCS, a surgeon oriented a specimen by placing a stitch at the 12 and $3 o^{\prime}$ clock reference positions. The specimen was then measured and inked in several colors corresponding to the six margins of interest: four peripheral parenchymal margins (medial, lateral, superior, and inferior) and two non-breast parenchymal margins (superficial and deep). If necessary, frozen biopsies were created during the operation. If any peripheral parenchymal margins such as the medial, lateral, superior, or inferior margin showed tumor involvement, the involved margin was further re-excised at the surgeon's discretion. For patients undergoing re-excision due to positive margins, we analyzed the margins from the re-excised specimen. Any patients who had undergone a mastectomy due to margin involvement, were excluded from the analysis.

A negative margin was defined as no ink on the tumor. A positive margin was defined as any invasive or in situ carcinoma on the inked margins of removed tissue. The study participants were divided into three groups according to their final margin status: group 1 (negative margin group), which included patients with a clear resection margin on all sections after BCS; group 2 (positive superficial and / or deep margin group), which included patients who had positive margins with only superficial and/or deep edges of the resected specimen; and group 3 (positive peripheral parenchymal margin group), which included patients with positive margins with parenchymal (medial, lateral, superior, and inferior) margins with or without superficial and / or deep resection margin involvement (Fig. 1).

All patients underwent whole-breast RT with tangential opposing fields. The median whole breast dose was $50.4 \mathrm{~Gy}$ in 28 daily fractions. The boost dose to the surgical cavity was determined according to the margin status. Group 1 patients received a boost RT of 10 Gy in 4-5 daily fractions. Patients with a positive margin as ductal carcinoma in situ or invasive carcinoma received 12.5 or $15 \mathrm{~Gy}$ in five or six daily fractions (groups 2 and 3). There was no difference in RT technique 


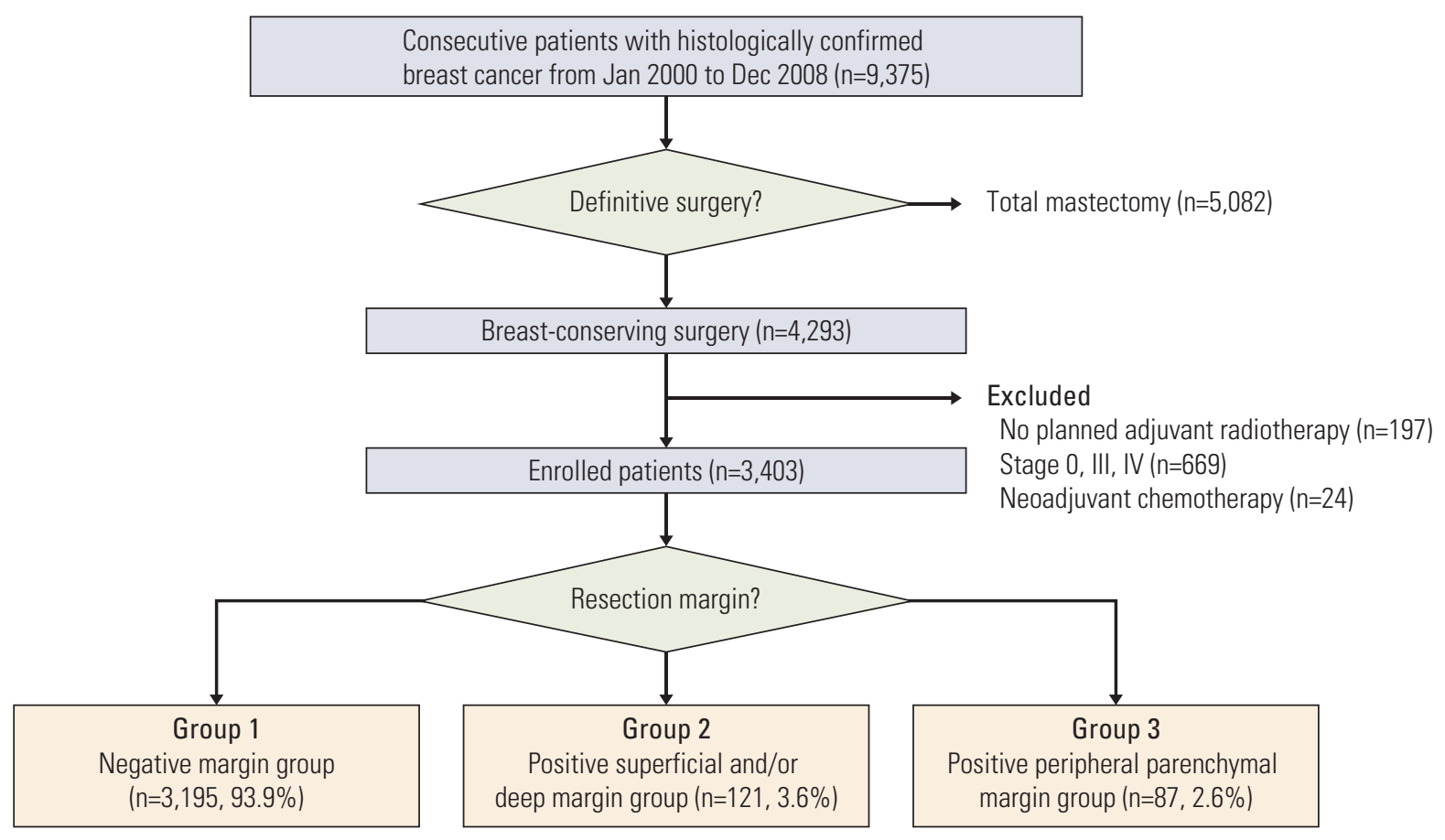

Fig. 1. Overview of the study population comprised of primary breast cancer patients.

and dose between the groups 2 and 3 .

LR-free survival was defined as the time from surgery to the first appearance of recurrence in the ipsilateral breast, including the skin or chest wall. Breast cancer-specific survival (BCSS) was defined as the time from surgery to death from breast cancer. Clinicopathological characteristics were compared between the three groups using the chi-square test and ANOVA. Survival curves were generated using the Kaplan-Meier method, and the significance of survival differences was verified using the log-rank test. The Cox proportional-hazards model was used to evaluate the independent prognostic effect of the surgical resection margin status on LR. Adjusted variables included patient age at diagnosis, tumor size, lymph node status, histologic grade, EIC presentation, hormone receptor status, adjuvant chemotherapy, and surgical resection margin status. Unless stated otherwise, the data are presented as mean \pm standard deviation, and the cutoff for statistical significance was set at $\mathrm{p}<0.05$. All statistical analyses were performed using SPSS ver. 21.0 (IBM Corp., Armonk, NY).

\section{Results}

\section{Clinicopathological characteristics}

A total of 3,427 patients diagnosed with stage 1 and 2 invasive breast cancer were treated with BCS followed by RT at our hospital during the study period. Of these patients, 24 who received neoadjuvant chemotherapy were excluded from the study cohort. The final analysis included 3,403 patients. Of the 3,403 patients, 3,195 (93.9\%) had negative margins (group 1), $121(3.6 \%)$ had positive superficial and/or deep margins (group 2), and the remaining 87 (2.6\%) had positive conventional peripheral parenchymal margins (group 3) (Fig. 1). The three study groups did not significantly differ from one another with respect to age, tumor size, nodal status, or HER2 status. Groups 2 and 3 had greater proportions of patients with higher histologic grade, positive EIC, positive hormone receptor status, hormone therapy, and without chemotherapy compared to group 1 . The details of the patient characteristics are summarized in Table 1.

\section{Prognostic value of the surgical resection margin status}

In the Cox proportional hazards model, statistically significant predictors for LR were younger age $(<40$ years vs. $\geq 40$ 
Table 1. Baseline characteristics of the study patients

\begin{tabular}{|c|c|c|c|c|}
\hline Characteristic & $\begin{array}{c}\text { Negative } \\
\text { margin (group 1) } \\
(n=3,195)\end{array}$ & $\begin{array}{l}\text { Positive superficial } \\
\text { and/or deep margin } \\
\text { (group } 2)(n=121)\end{array}$ & $\begin{array}{l}\text { Positive peripheral } \\
\text { parenchymal margin } \\
\text { (group 3) (n=87) }\end{array}$ & p-value \\
\hline Age at diagnosis (yr) & $47(19-78)$ & $45(29-71)$ & $45(30-73)$ & 0.47 \\
\hline \multicolumn{5}{|l|}{ Follow-up period (mo) } \\
\hline Median & 88 & 81 & 88 & 0.86 \\
\hline Mean \pm SD & $92.6 \pm 26.6$ & $91.0 \pm 25.7$ & $91.7 \pm 23.7$ & \\
\hline \multicolumn{5}{|l|}{ Tumor size $(\mathrm{cm})$} \\
\hline$\leq 2$ & $2,356(73.7)$ & $89(73.6)$ & $70(80.5)$ & 0.37 \\
\hline$>2$ & $839(26.3)$ & $32(26.4)$ & $17(19.5)$ & \\
\hline \multicolumn{5}{|l|}{ Node metastasis } \\
\hline Negative & $2,419(75.7)$ & $88(72.7)$ & $71(81.6)$ & 0.68 \\
\hline Positive & $776(24.3)$ & $33(27.3)$ & $16(18.4)$ & \\
\hline \multicolumn{5}{|l|}{ Histologic grade } \\
\hline $1 / 2$ & $1,959(66.1)$ & $84(74.3)$ & $63(77.8)$ & 0.02 \\
\hline 3 & $1,003(33.9)$ & $29(25.7)$ & $18(22.2)$ & \\
\hline Unknown & 5 & 0 & 0 & \\
\hline \multicolumn{5}{|l|}{ EIC present } \\
\hline No & $2,481(81.3)$ & $86(71.7)$ & $46(55.4)$ & $<0.001$ \\
\hline Yes & $571(18.7)$ & $34(28.3)$ & $37(44.6)$ & \\
\hline Unknown & 143 & 1 & 4 & \\
\hline \multicolumn{5}{|c|}{ Hormone receptor status } \\
\hline Negative & $993(31.3)$ & $21(17.4)$ & $16(18.4)$ & $<0.001$ \\
\hline Positive & $2,180(68.7)$ & $100(82.6)$ & $71(81.6)$ & \\
\hline Unknown & 21 & 0 & 0 & \\
\hline \multicolumn{5}{|l|}{ HER2 status } \\
\hline Negative & $2,244(80.4)$ & $86(78.9)$ & $59(80.8)$ & 0.89 \\
\hline Positive & $546(19.6)$ & $23(21.1)$ & $14(19.2)$ & \\
\hline Unknown & 371 & 12 & 14 & \\
\hline \multicolumn{5}{|l|}{ Hormone therapy } \\
\hline No & $880(27.8)$ & $20(16.5)$ & 15 (18.6) & 0.005 \\
\hline Yes & $2,285(72.2)$ & $101(83.5)$ & $67(81.4)$ & \\
\hline Unknown & 30 & 0 & 1 & \\
\hline \multicolumn{5}{|l|}{ Chemotherapy } \\
\hline No & $1,277(40.0)$ & $61(50.4)$ & $46(52.9)$ & 0.005 \\
\hline Yes & $1,918(60.0)$ & $60(49.6)$ & $41(47.1)$ & \\
\hline Unknown & 1 & 0 & 0 & \\
\hline
\end{tabular}

Values are presented as median (range) or number (\%) unless otherwise indicated. SD, standard deviation; EIC, extensive intraductal component; HER2, human epidermal growth factor receptor 2.

years) (hazard ratio [HR], 2.59; 95\% confidence interval [CI], 1.64 to $4.10 ; \mathrm{p}<0.001)$, negative hormone receptor (HR, 2.90; 95\% CI, 1.65 to 5.12; $\mathrm{p}<0.001)$, and peripheral parenchymal margin involvement (group 3) (HR, 4.78; 95\% CI, 2.27 to 10.09; $\mathrm{p}<0.001)$. Positive superficial and/or deep margin involvement (group 2) were not significant predictors for LR (HR, $0.66 ; 95 \% \mathrm{CI}, 0.16$ to $2.72 ; \mathrm{p}=0.566$ ) (Table 2, S1 Table). Overall, there was a $2.9 \%$ rate of LR $(99 / 3,403)$ with a median follow up of 88 months (range, 1 to 188 months): $2.8 \%(89 / 3,195)$ in the negative margin group (group 1), 1.7\% (2/121) in the positive superficial and/or deep margin group (group 2), and 9.2\% (8/87) in the positive peripheral parenchymal margin group (group 3). There were no skin or chest wall recurrences, and only two patients showed ipsilateral breast tumor recurrence in group 2 (Table 3). The 5-year LR-free survival of these groups were $1.9 \%, 1.7 \%$, and $7.4 \%$, respectively, with significantly poorer LR-free survival in group 3 ( $\mathrm{p}=0.001$ for groups 1 vs. 3 , and $p=0.010$ for groups 2 vs. 3). No difference in 
Table 2. Multivariate analysis of the predictive factors for local recurrence

\begin{tabular}{|c|c|c|}
\hline Variable & $\mathrm{HR}(95 \% \mathrm{CI})$ & p-value \\
\hline Age at diagnosis (yr) & & $<0.001$ \\
\hline$\geq 40$ & 1 & \\
\hline$<40$ & $2.59(1.64-4.10)$ & \\
\hline Tumor size $(\mathrm{cm})$ & & 0.022 \\
\hline$\leq 2$ & 1 & \\
\hline$>2$ & $1.78(1.09-2.92)$ & \\
\hline Node metastasis & & 0.613 \\
\hline No & 1 & \\
\hline Yes & $0.86(0.48-1.54)$ & \\
\hline Histologic grade & & 0.880 \\
\hline $1 / 2$ & 1 & \\
\hline 3 & $0.96(0.57-1.63)$ & \\
\hline EIC present & & 0.410 \\
\hline No & 1 & \\
\hline Yes & $1.26(0.73-2.17)$ & \\
\hline Hormone receptor status & & $<0.001$ \\
\hline Positive & 1 & \\
\hline Negative & $2.90(1.65-5.12)$ & \\
\hline Adjuvant chemotherapy & & 0.139 \\
\hline No & 1 & \\
\hline Yes & $0.62(0.33-1.17)$ & \\
\hline Resection margin involvement & & $<0.001$ \\
\hline Group 1 & 1 & \\
\hline Group 2 & $0.66(0.16-2.72)$ & 0.566 \\
\hline Group 3 & $4.78(2.27-10.09)$ & $<0.001$ \\
\hline
\end{tabular}

$\mathrm{HR}$, hazard ratio; $\mathrm{CI}$, confidence interval; EIC, extensive intraductal component.

LR-free survival was observed between group 1 and group 2 ( $\mathrm{p}=0.401)$. The 5-year BCSS of groups 1, 2, and 3 was $97.5 \%$, $99.2 \%$, and $98.8 \%$, respectively, with no statistically significant differences between these groups ( $\mathrm{p}=0.107$ ) (Fig. 2).

\section{Discussion}

Our present study finding have indicated that the prognostic impact of positive superficial and/ or deep margins on local failure is not significant in stage 1 and 2 breast cancer treated with BCS followed by RT. This result has valuable clinical implications in that the routine removal of structures above and below a targeted tumor during BCS may cause unsatisfactory cosmetic results, particularly in Asian women with small breasts. In addition, if oncologically safe, surgical strategies with less extensive or destructive resection could improve the postoperative quality of life and lower the prevalence of unnecessary oncoplastic procedures to restore an inadequately conserved breast.

LR rates have generally been reported at $8 \%-21 \%$ following BCS [10-14]. In the present study, the 5-year LR rate in the positive superficial and/or deep margin group was similar to that in the negative margin group (1.7\% vs. $1.9 \%)$ and significantly lower than that in the positive peripheral parenchymal margin group (1.7\% vs. $7.4 \%$ ). The relatively higher prevalence of superficial and/or deep margins in our study is related to our center's surgical strategies for BCS. Tumor resection without skin involvement by resecting only the breast parenchyma and leaving the skin with the subcutaneous fat below could increase the likelihood of a positive superficial resection margin. Likewise, for a tumor without chest wall muscle involvement, leaving the posterior fascia and the retromammary fat above could also increase the likelihood of a positive deep resection margin. For these reasons, some surgeons remain concerned about the uncertainty of oncological safety of these procedures and thus perform a full-thickness excision by resecting from the skin to the pos- 
Table 3. Detailed description of the resection margin status and LR type according to the study groups

\begin{tabular}{|c|c|c|c|c|c|c|c|c|c|c|}
\hline \multirow{3}{*}{ Group } & \multicolumn{5}{|c|}{ Resection margin status } & \multicolumn{5}{|c|}{ LR site } \\
\hline & \multirow[b]{2}{*}{ Free } & \multirow[b]{2}{*}{ In situ } & \multirow[b]{2}{*}{ Invasive } & \multirow{2}{*}{$\begin{array}{l}\text { Both in } \\
\text { situ and } \\
\text { invasive }\end{array}$} & \multirow[b]{2}{*}{ NA } & \multirow{2}{*}{$\begin{array}{c}\text { Total } \\
\text { No. of } \\
\text { LRs }\end{array}$} & \multicolumn{2}{|c|}{ In breast } & \multirow[b]{2}{*}{ Skin } & \multirow[b]{2}{*}{$\begin{array}{l}\text { Ches } \\
\text { wall }\end{array}$} \\
\hline & & & & & & & $\begin{array}{c}\text { Same } \\
\text { quadrant }\end{array}$ & $\begin{array}{c}\text { Other } \\
\text { quadrant }\end{array}$ & & \\
\hline $\begin{array}{l}\text { Group 1: no involvement on } \\
\text { all resection margins }(n=3,195)\end{array}$ & 3,195 & - & - & - & - & 89 & 67 & 20 & 1 & 1 \\
\hline \multirow{4}{*}{$\begin{array}{l}\text { Group 2: involvement on } \\
\text { superficial and/or deep } \\
\text { resection margins }(\mathrm{n}=121)\end{array}$} & - & 31 & - & - & - & 1 & 1 & - & - & - \\
\hline & - & - & 76 & - & - & 1 & - & 1 & - & - \\
\hline & - & - & - & 1 & - & 0 & - & - & - & - \\
\hline & - & - & - & - & 13 & 0 & - & - & - & - \\
\hline \multirow{4}{*}{$\begin{array}{l}\text { Group 3: involvement on } \\
\text { conventional peripheral } \\
\text { parenchymal resection } \\
\text { margins }(\mathrm{n}=87)\end{array}$} & - & 73 & - & - & - & 7 & 4 & 3 & - & - \\
\hline & - & - & 9 & - & - & 0 & - & - & - & - \\
\hline & - & - & - & 4 & - & 1 & 1 & - & - & - \\
\hline & - & - & - & - & 1 & 0 & - & - & - & - \\
\hline
\end{tabular}

LR, local recurrence; NA, not available.
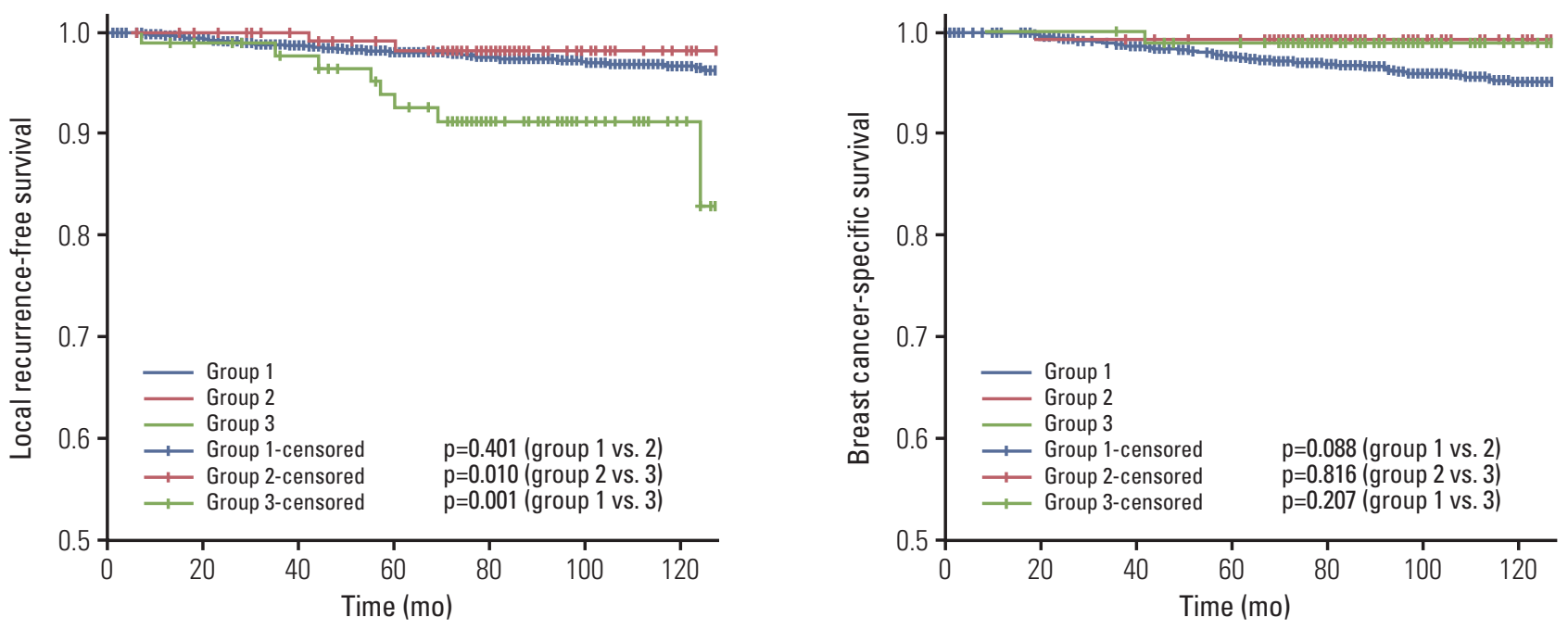

Fig. 2. Kaplan-Meier plots of local recurrence-free survival and breast cancer-specific survival according to margin status.

terior fascia. However, we believe that our surgical principle has no negative impact on local management, and the evidence from the present study can be helpful to surgeons in making a decision whether to resect only the breast parenchyma and leave the subcutaneous and retromammary fat for a more natural breast shape in selected patients.

A previous MEDLINE search revealed that few studies have explored the anatomic location of the involved margin as an indicator to forgo further resection before radiation [9]. Additional resection leads to delayed RT and poor cosmetic 
results [6,15]. Moreover, Mullen et al. [16] reported that the re-excision of an involved anterior (superficial) resection margin after BCS was significantly less likely to lead to further disease. As revealed by our present findings, superficial and / or deep resection margin involvements have no relationship with LR, which suggests a rationale for leaving subcutaneous and retromammary fat during the operation and omitting additional resection after BCS for patients with positive superficial and/or deep resection margins.

Oncoplastic surgery has contributed to widening the range of breast-conserving surgery. The oncologic safety of oncoplastic surgery with breast conservation has also been demonstrated, and various types of oncoplastic breast-conserving surgery have been performed $[17,18]$. Oncoplastic surgery has many advantages, but also disadvantages such as relatively larger tissue excision, more complications, longer operation time, and more expensive surgery costs than breast-conserving surgery alone [19]. Oncoplastic surgery is useful in obtaining negative margins with wide resection $[20,21]$. However, if the conservation of subcutaneous or retromammary fat can predict a good cosmetic outcome, more sophisticated techniques and additional timeconsuming surgery may not always be necessary.

In this study, the radiation dose differed according to the margin status. Patients with a positive margin as ductal carcinoma in situ or invasive carcinoma received a tumor bed boost of 12.5 or 15 Gy at 2.5 Gy per fraction, respectively. There was no difference in RT between the groups 2 and 3, hence radiation was not a factor that affected the LR between the two groups.

Younger age, usually defined as below 40 years, is associated with an increased LR risk after BCS as compared to older women $[14,22]$. Likewise, the multivariate Cox regression analysis in our present study suggested that a younger age at breast cancer diagnosis ( $<40$ years old) is a significant risk factor for $\mathrm{LR}(\mathrm{HR}, 2.59 ; \mathrm{p}<0.001)$.

Koca et al. [23] previously reported the presence of an EIC affected the positive margin status after BCS. The presence of an EIC has been associated with an increased risk of LR in some studies, even in the presence of negative margins $[14,24]$. However, the results of other studies did not support these findings $[10,25]$. In our present study, we found that patients with an EIC were more likely to have positive resec- tion margins. However, we also found that the presence of an EIC was not associated with an increased risk of local failure.

A negative hormone receptor was a predictive factor for LR in our study. Various studies to date have reported an association between breast cancer subtype and tumor recurrence. In some studies, triple-negative breast cancer had an increased risk of LR $[26,27]$. A recent meta-analysis indicated that the loco-regional recurrence rate was significantly higher in hormone receptor-negative tumors compared with nontriple negative tumors [28], which is coincident with our finding. Our present analysis had some limitations, including its single-center retrospective design with some biases in patient and treatment selection and non-centralized pathologic review. In addition, the small number of LR events limited the statistical power of our analysis and consequently yielded large standard errors. Despite these limitations, the strength of our current study was that we analyzed a large cohort of contemporarily-treated BCS patients, for whom detailed information was available on the specific anatomical margin (including superficial and deep margin) location and treatments.

In conclusion, superficial and/or deep margin involvement following BCS is not an important predictor for LR. Extensive excision of skin, subcutaneous fat, retromammary fat, or pectoral fascia does not need to be routinely performed to achieve negative superficial and/or deep margin status during BCS.

\section{Electronic Supplementary Material}

Supplementary materials are available at Cancer Research and Treatment website (http://www.e-crt.org).

\section{Conflicts of Interest}

Conflict of interest relevant to this article was not reported.

\section{Acknowledgments}

This study was supported by a grant of the Korean Health Technology R\&D Project, Ministry of Health \& Welfare, Republic of Korea (HI14C1061).

\section{References}

1. Forrest AP, Stewart HJ, Everington D, Prescott RJ, McArdle CS, Harnett AN, et al. Randomised controlled trial of conservation therapy for breast cancer: 6-year analysis of the Scottish trial. Scottish Cancer Trials Breast Group. Lancet. 1996;348: 708-13.

2. Malmstrom P, Holmberg L, Anderson H, Mattsson J, Jonsson 
PE, Tennvall-Nittby L, et al. Breast conservation surgery, with and without radiotherapy, in women with lymph node-negative breast cancer: a randomised clinical trial in a population with access to public mammography screening. Eur J Cancer. 2003;39:1690-7.

3. Ko BS, Noh WC, Kang SS, Park BW, Kang EY, Paik NS, et al. Changing patterns in the clinical characteristics of korean breast cancer from 1996-2010 using an online nationwide breast cancer database. J Breast Cancer. 2012;15:393-400.

4. Clarke M, Collins R, Darby S, Davies C, Elphinstone P, Evans $\mathrm{V}$, et al. Effects of radiotherapy and of differences in the extent of surgery for early breast cancer on local recurrence and 15-year survival: an overview of the randomised trials. Lancet. 2005;366:2087-106.

5. Houssami N, Macaskill P, Marinovich ML, Dixon JM, Irwig L, Brennan ME, et al. Meta-analysis of the impact of surgical margins on local recurrence in women with early-stage invasive breast cancer treated with breast-conserving therapy. Eur J Cancer. 2010;46:3219-32.

6. Singletary SE. Surgical margins in patients with early-stage breast cancer treated with breast conservation therapy. Am J Surg. 2002;184:383-93.

7. Coates AS, Winer EP, Goldhirsch A, Gelber RD, Gnant M, Piccart-Gebhart $\mathrm{M}$, et al. Tailoring therapies: improving the management of early breast cancer: St Gallen International Expert Consensus on the Primary Therapy of Early Breast Cancer 2015. Ann Oncol. 2015;26:1533-46.

8. NIH consensus conference. Treatment of early-stage breast cancer. JAMA. 1991;265:391-5.

9. McIntosh A, Freedman G, Eisenberg D, Anderson P. Recurrence rates and analysis of close or positive margins in patients treated without re-excision before radiation for breast cancer. Am J Clin Oncol. 2007;30:146-51.

10. Fisher ER, Sass R, Fisher B, Gregorio R, Brown R, Wickerham L. Pathologic findings from the National Surgical Adjuvant Breast Project (protocol 6). II. Relation of local breast recurrence to multicentricity. Cancer. 1986;57:1717-24.

11. Veronesi U, Marubini E, Mariani L, Galimberti V, Luini A, Veronesi $\mathrm{P}$, et al. Radiotherapy after breast-conserving surgery in small breast carcinoma: long-term results of a randomized trial. Ann Oncol. 2001;12:997-1003.

12. Lupe K, Truong PT, Alexander C, Lesperance M, Speers C, Tyldesley S. Subsets of women with close or positive margins after breast-conserving surgery with high local recurrence risk despite breast plus boost radiotherapy. Int J Radiat Oncol Biol Phys. 2011;81:e561-8.

13. Heimann R, Powers C, Halpem HJ, Michel AG, Ewing CA, Wyman $\mathrm{B}$, et al. Breast preservation in stage I and II carcinoma of the breast. The University of Chicago experience. Cancer. 1996;78:1722-30.

14. Moran MS, Schnitt SJ, Giuliano AE, Harris JR, Khan SA, Horton J, et al. Society of Surgical Oncology-American Society for Radiation Oncology consensus guideline on margins for breast-conserving surgery with whole-breast irradiation in stages I and II invasive breast cancer. Ann Surg Oncol. 2014;21:704-16.
15. Cellini C, Hollenbeck ST, Christos P, Martins D, Carson J, Kemper S, et al. Factors associated with residual breast cancer after re-excision for close or positive margins. Ann Surg Oncol. 2004;11:915-20.

16. Mullen R, Macaskill EJ, Khalil A, Elseedawy E, Brown DC, Lee $\mathrm{AC}$, et al. Involved anterior margins after breast conserving surgery: is re-excision required? Eur J Surg Oncol. 2012;38: 302-6.

17. Losken A, Dugal CS, Styblo TM, Carlson GW. A meta-analysis comparing breast conservation therapy alone to the oncoplastic technique. Ann Plast Surg. 2014;72:145-9.

18. De Lorenzi F, Hubner G, Rotmensz N, Bagnardi V, Loschi P, Maisonneuve $\mathrm{P}$, et al. Oncological results of oncoplastic breastconserving surgery: Long term follow-up of a large series at a single institution: A matched-cohort analysis. Eur J Surg Oncol. 2016;42:71-7.

19. Tenofsky PL, Dowell P, Topalovski T, Helmer SD. Surgical, oncologic, and cosmetic differences between oncoplastic and nononcoplastic breast conserving surgery in breast cancer patients. Am J Surg. 2014;207:398-402.

20. Chakravorty A, Shrestha AK, Sanmugalingam N, Rapisarda F, Roche N, Querci Della Rovere G, et al. How safe is oncoplastic breast conservation? Comparative analysis with standard breast conserving surgery. Eur J Surg Oncol. 2012;38:395-8.

21. Kaur N, Petit JY, Rietjens M, Maffini F, Luini A, Gatti G, et al. Comparative study of surgical margins in oncoplastic surgery and quadrantectomy in breast cancer. Ann Surg Oncol. 2005;12:539-45.

22. de Bock GH, van der Hage JA, Putter H, Bonnema J, Bartelink $\mathrm{H}$, van de Velde CJ. Isolated loco-regional recurrence of breast cancer is more common in young patients and following breast conserving therapy: long-term results of European Organisation for Research and Treatment of Cancer studies. Eur J Cancer. 2006;42:351-6.

23. Koca B, Kuru B, Yuruker S, Gokgul B, Ozen N. Factors affecting surgical margin positivity in invasive ductal breast cancer patients who underwent breast-conserving surgery after preoperative core biopsy diagnosis. J Korean Surg Soc. 2013;84: 154-9.

24. Schnitt SJ, Connolly JL. Processing and evaluation of breast excision specimens: a clinically oriented approach. Am J Clin Pathol. 1992;98:125-37.

25. Cabioglu N, Hunt KK, Sahin AA, Kuerer HM, Babiera GV, Singletary SE, et al. Role for intraoperative margin assessment in patients undergoing breast-conserving surgery. Ann Surg Oncol. 2007;14:1458-71.

26. Gabos Z, Thoms J, Ghosh S, Hanson J, Deschenes J, Sabri S, et al. The association between biological subtype and locoregional recurrence in newly diagnosed breast cancer. Breast Cancer Res Treat. 2010;124:187-94.

27. Foulkes WD, Smith IE, Reis-Filho JS. Triple-negative breast cancer. N Engl J Med. 2010;363:1938-48.

28. Lowery AJ, Kell MR, Glynn RW, Kerin MJ, Sweeney KJ. Locoregional recurrence after breast cancer surgery: a systematic review by receptor phenotype. Breast Cancer Res Treat. 2012;133:831-41. 